\title{
ANALISIS MATRIKS BOSTON CONSULTING GROUP (BCG) UNTUK MEMENANGKAN STRATEGI ORGANISASI (Studi Kasus Perguruan Tinggi di Kopertis Wilayah III - DKI Jakarta)
}

\author{
Haryadi Sarjono; Engkos Achmad Kuncoro \\ Management Department, School of Business Management, BINUS University \\ Jln. K. H. Syahdan No. 9, Palmerah, Jakarta Barat 11480 \\ haryadisarjono@yahoo.com; eak@binus.edu
}

\begin{abstract}
This research intends to know position of market growth in higher education, especially Sekolah Tinggi, based on market share, using BCG metrics. Unit analysis is all private higher educations in Kopertis III - DKI Jakarta, consisting of University, Sekolah Tinggi, Institute, and Academics. The object of analysis is the number of new student admission. Method of data collection in this paper is field research including observation and literature research method. The secondary data used in this study is data from Kopertis region III. Based on the results of the study, it is obtained Sekolah Tinggi for the academic year 2008 and 2009 is in quadrant III (Cash Cow).
\end{abstract}

Keywords: BCG, Matrix, Kopertis region III-DKI Jakarta, higher education

\begin{abstract}
ABSTRAK
Penelitian ini bertujuan untuk mengetahui posisi tingkat pertumbuhan pasar pada perguruan tinggi khususnya Sekolah Tinggi berdasarkan market share, menggunakan matriks BCG. Unit analisis adalah semua perguruan tinggi swasta yang termasuk dalam Kopertis Wilayah III - DKI Jakarta, yang terdiri dari Universitas, Sekolah Tinggi, Institut, dan Akademi. Objek analisis adalah jumlah penerimaan mahasiswa baru. Metode pengumpulan data yang dilakukan dalam penulisan ini adalah dengan metode riset lapangan yang meliputi kegiatan observasi dan dengan metode riset kepustakaan. Data sekunder yang digunakan dalam penulisan ini data dari Kopertis wilayah III. Berdasarkan hasil penelitian, didapatkan bahwa Sekolah tinggi untuk tahun ajaran 2008 dan 2009 berada pada kuadran III (Cash Cow).
\end{abstract}

Kata kunci: BCG, matriks, Kopertis wilayah III-DKI Jakarta, perguruan tinggi 


\section{PENDAHULUAN}

Salah satu kunci keberhasilan dari perencanaan strategi adalah pada pemilihan pasar dan penentuan berkompetisi di tengah persaingan yang ada (Hooley, Moller \& Broderick,1998; Sashi \& Stern, 1995). Letak dari persaingan adalah diferensiasi produk dan jasa dalam pasar yang terpilih bagi para pesaing mereka. Mengacu pada ide Porter (1980) mengenai keunggulan bersaing dapat dicapai melalui bermacam strategi salah satunya dengan strategi bisnis baik itu cost leadership, differentiation maupun focus.

Mengelola pendidikan tinggi sekarang ini sama seperti mengelola sebuah perusahaan, dihadapkan pada dua dilema: apakah akan memperkuat mutu atau memperluas akses, yang keduanya sangat dibutuhkan oleh sebuah perguruan tinggi sebagai organisasi yang berlatar bisnis (Swa, Oktober 2011). Akses masyarakat kelas menengah ke bawah terhadap perguruan tinggi sekarang ini memang rendah. Pada 2008 hanya 17\% yang diterima di Perguruan Tinggi Negeri (PTN), selebihnya kelas menengah ke atas dan tragisnya, persentase tersebut terus menurun menjadi 15-16\%. Artinya, hanya 15 dari 100 orang warga miskin yang bisa kuliah (Hanif Ghafur, staf Menteri Pendidikan Nasional, 2011). Sedangkan Darmaningtyas (2011) menilai kondisi sekarang ini sesungguhnya lebih parah lagi. Jumlah golongan miskin di PTN dan perguruan tinggi badan hukum milih negara (PT.BHMN) pada 2010 hanya sekitar 4\% saja. Sebagai contoh, Ichlasul Amal (mantan rektor UGM) mengatakan kemajuan teknologi, membuat masyarakat miskin susah untuk akses ke PT, yang pendaftaran calon mahasiswanya harus secara online, ditambah uang pangkal maupun SPP juga semakin mahal.

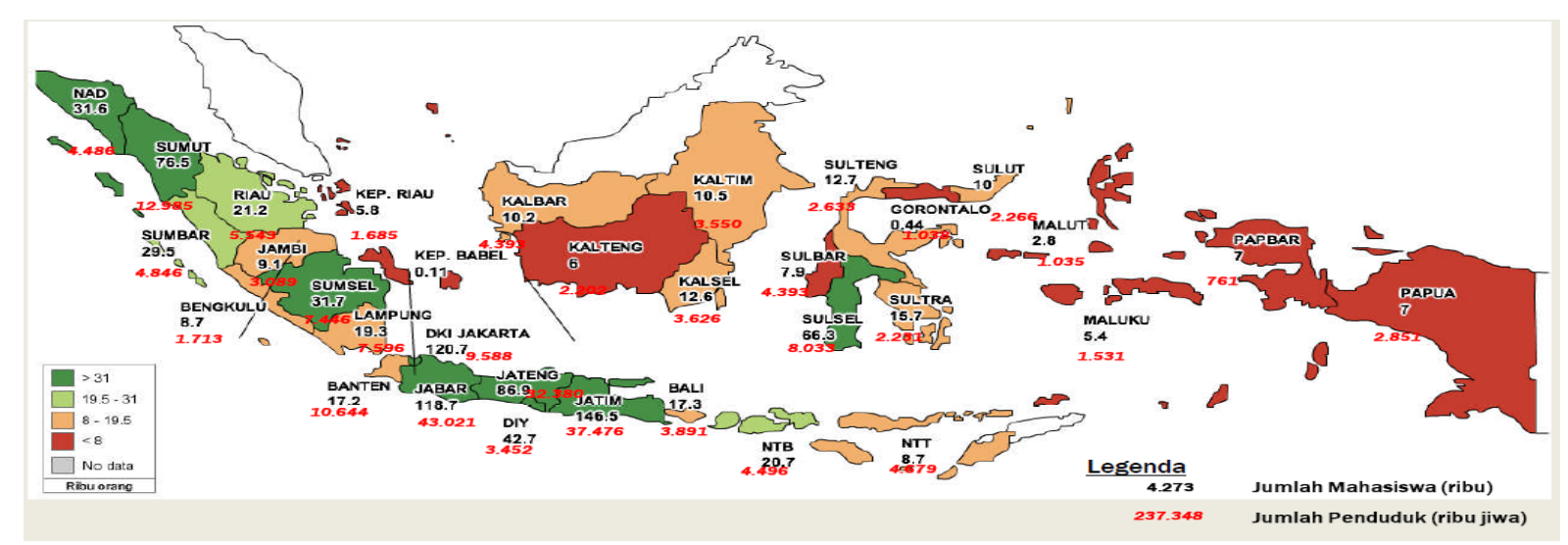

Gambar 1 Tabel Jumlah Mahasiswa dan Jumlah Penduduk

Di dalam perguruan tinggi yang ada di Kopertis Wilayah III - DKI Jakarta, yang sekolah tinggi termasuk di dalamnya menjadi penting keberadaannya. Oleh karena itu, dalam penelitian ini akan dibahas mengenai posisi Sekolah tinggi dibandingkan Universitas, Akademi, dan Institut berdasarkan matriks BCG

\section{Identifikasi Masalah}

Bagaimana posisi Sekolah tinggi terhadap perguruan tinggi lainnya, di antaranya Universitas, Akademi, dan Institut yang berada di Kopertis Wilayah III - DKI Jakarta dengan pendekatan matriks BCG? Bagaimana strategi yang dilakukan oleh Sekolah Tinggi di Kopertis wilayah III-DKI Jakarta, berdasarkan pendekatan matriks BCG? Bagaimana pangsa pasar dari Sekolah Tinggi di Kopertis wilayah III - DKI Jakarta? Bagaimana market growth dari Sekolah Tinggi yang berada di Kopertis wilayah III - DKI Jakarta? 


\section{Landasan Teori}

Matriks Boston Consulting Group (BCG) secara grafis menunjukkan perbedaan di antara berbagai divisi dalam posisi pangsa pasar relatif dan tingkat pertumbuhan industri. Matriks BCG memungkinkan organisasi multidivisi untuk mengelola portofolio bisnisnya dengan mempertimbangkan posisi pangsa pasar relatif dan tingkat pertumbuhan industri di masing-masing divisi relatif terdahap divisi lain dalam organisasi. Posisi pangsa pasar relatif (relative market share position) didefinisikan sebagai rasio dari pangsa pasar satu divisi tertentu terhadap pangsa pasar yang dimiliki oleh pesaing terbesar dalam industri tersebut.

Posisi pangsa pasar relatif diberikan pada sumbu X dari matriks BCG. Titik tengah dari sumbu $\mathrm{X}$ biasanya dibuat 0,50 sama dengan divisi yang memiliki separuh pangsa pasar dari perusahaan pemimpin dalam industri. Sumbu Y menggambarkan tingkat pertumbuhan industri dalam penjualan yang diukur dalam bentuk persentase. Persentase tingkat pertumbuhan pada sumbu $\mathrm{Y}$ dapat berkisar antara -20 hingga +20 persen, dengan 0,0 sebagai titik tengah. Angka kisaran ini pada sumbu $X$ dan $\mathrm{Y}$ sering kali digunakan, tetapi angka lainnya dapat dibuat bisa dianggap sesuai untuk organisasi tertentu.

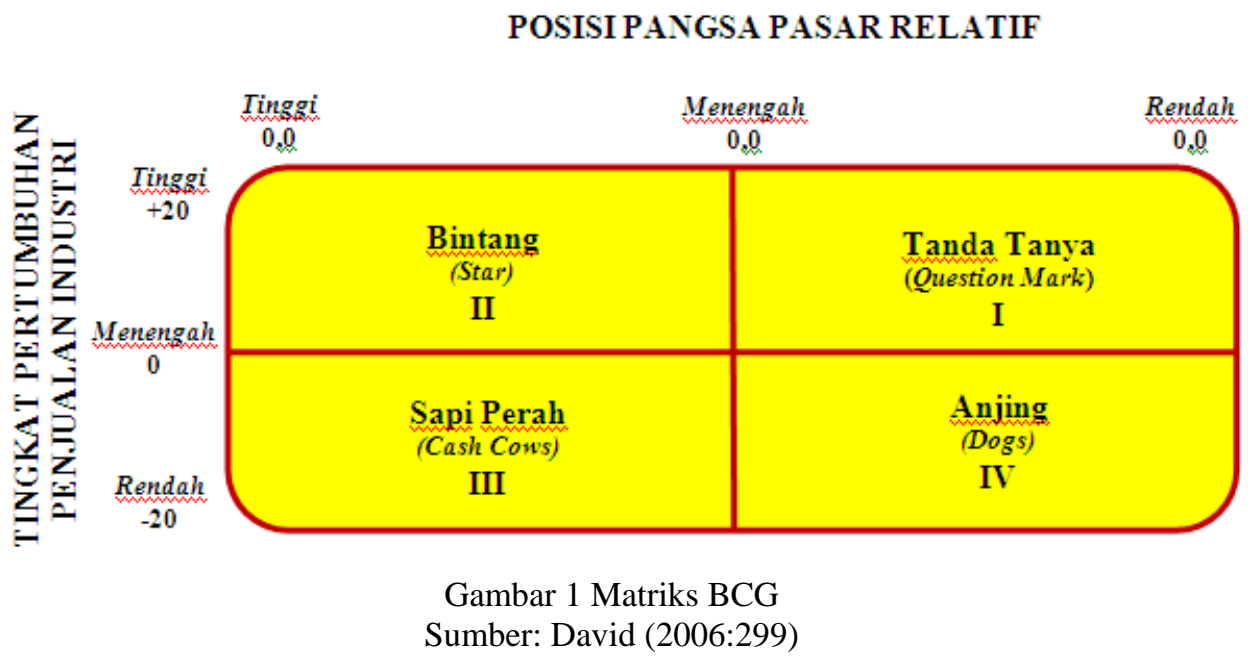

Table 1 Prescriptions of the BCG Growth Share Matrix

\begin{tabular}{l|c|c|l}
\hline \multicolumn{1}{c|}{ Category } & Growth & Share & \multicolumn{1}{c}{ Prescription } \\
\hline Star & High & High & $\begin{array}{l}\text { The main focus of star businesses is to protect their market shares and } \\
\text { thus get a bigger portion of the market growth than competitors. Star } \\
\text { businesses will ultimately turn into cash-cows }\end{array}$ \\
\hline Cash Cow & Low & High & $\begin{array}{l}\text { Characterized by high profit and cash generation. The remaining cash } \\
\text { after covering costs to run the business and to protect the share in a } \\
\text { mature market should be redistributed to other businesses. }\end{array}$ \\
\hline Dog & Low & Low & $\begin{array}{l}\text { These units have high cash needs and firms should therefore do } \\
\text { whatever is necessary to increase market share or divest quickly. }\end{array}$ \\
\hline $\begin{array}{l}\text { Often generate poor profits and cash needs are frequently higher than } \\
\text { the cash that is generated. To improve the overall performance, firms } \\
\text { should minimize the proportion of their assets that remain in this } \\
\text { category by focusing on a specialized segment, harvesting by cutting } \\
\text { costs and maximizing cash flow by divestment or liquidation }\end{array}$ \\
\hline
\end{tabular}

Sumber: http://faculty.unlv.edu/phelan/Research/BCG.pdf 


\section{Kategori BCG (David, 2006:298)}

\section{Question Mark}

Divisi dalam kuadran I, memiliki posisi pangsa pasar relatif rendah, tetapi mereka bersaing dalam industri yang bertumbuh pesat. Biasanya kebutuhan kas perusahaan ini tinggi dan pendapatan kasnya rendah. Bisnis ini disebut tanda tanya karena organisasi harus memutuskan apakah akan memperkuat divisi ini dengan menjalankan strategi intensif (penetrasi pasar, pengembangan pasar, atau pengembangan produk) atau menjualnya.

\section{Star}

Bisnis di kuadran II, mewakili peluang jangka panjang terbaik untuk pertumbuhan dan profitabilitas bagi organisasi. Divisi dengan pangsa pasar relatif yang tinggi dan tingkat pertumbuhan industri yang tinggi seharusnya menerima investasi yang besar untuk mempertahankan atau memperkuat posisi dominan mereka. Integrasi ke depan, ke belakang, dan horizontal; penetrasi pasar, pengembangan pasar; pengembangan produk dan joint venture adalah strategi yang sesuai untuk dipertimbangkan divisi ini.

\section{Cash Cow}

Divisi yang berpotensi di kuadran III, memiliki pangsa pasar relatif yang tinggi bersaing tetapi bersaing dalam industry yang pertumbuhannya lambat. Disebut Sapi perah karena mereka menghasilkan kas lebih dari yang dibutuhkannya, mereka sering kali diperah. Banyak sapi perah saat ini adalah bintang di masa lalu. Divisi sapi perah harus dikelola untuk mempertahankan posisi kuatnya selama mungkin, Pengembangan produk atau diversifikasi konsentris dapat menjadi strategi yang menarik untuk sapi perah yang kuat, tetapi ketika divisi sapi perah menjadi lemah, retrenchment atau diverstasi lebih sesuai untuk diterapkan.

\section{Dog}

Divisi kuadran IV dari organisasi memiliki pangsa pasar relatif yang rendah dan bersaing dalam industri yang pertumbuhannya rendah atau tidak tumbuh; mereka adalah Anjing dalam portofolio perusahaan. Karena posisi internal dan eksternalnya lemah, bisnis ini sering kali dilikuidasi, divestasi atau dipangkas dengan retrenchment. Ketika sebuah divisi menjadi anjing, retrenchment dapat menjadi strategi terbaik yang dapat dijalankan karena banyak anjing yang mencuat kembali, setelah pemangkasan biaya dan asset besar-besaran, menjadi bisnis yang mampu bertahan dan menguntungkan.

\section{Kelemahan BCG}

Matriks BCG seperti teknik analisis lainnya, memiliki beberapa kekurangan, antara lain: terlalu memusatkan perhatian pada arus kas, karakteristik investasi dan kebutuhan berbagai divisi organisasi; memandang semua bisnis sebagai Bintang, Sapi perah, Anjing atau Tanda tanya adalah terlalu menyederhanakan masalah, karena banyak bisnis yang berposisi tepat di tengah-tengah Matriks BCG, dan dengan demikian sebenarnya tidak mudah untuk di klasifikasikan; matriks BCG tidak menggambarkan jika berbagai divisi atau industri mereka tumbuh sepanjang waktu, jadi matriks tersebut tidak memiliki karakterikstik waktu; hanya memandang 2 variabel yang paling dominan, tetapi mengesampingkan variabel lainnya, seperti ukuran pasar dan keunggulan kompetitif yang juga merupakan hal penting dalam pembuatan keputusan strategis (David, 2006: 300). 


\section{METODE PENELITIAN}

Penelitian ini bertujuan untuk pertumbuhan pangsa pasar (market growth) dari Sekolah Tinggi, untuk mengetahui pangsa pasar dari Sekolah Tinggi yang berada di Kopertis wilayah III - DKI Jakarta, dan untuk mengetahui strategi yang akan dilakukan oleh Sekolah Tinggi berdasarkan pendekatan dari matriks Boston Consulting Group (BCG). Metode pengumpulan data yang dilakukan dalam penulisan ini adalah dengan metode riset lapangan yang meliputi kegiatan observasi dan riset kepustakaan. Data yang digunakan hanya data sekunder dari Kopertis Wilayah III - DKI Jakarta untuk periode tahun ajaran 2007, 2008 dan 2009.

Matriks BCG dilakukan berdasarkan data sekunder dari Kopertis wilayah III - DKI Jakarta, tahun ajaran 2007, 2008 dan 2009, untuk mengetahui pertumbuhan pangsa pasar dan pangsa pasar. Analisis data menggunakan matriks BCG untuk mengetahui posisi tingkat pertumbuhan pasar pada Sekolah Tinggi berdasarkan market share.

\section{HASIL DAN PEMBAHASAN}

Metode matriks BCG digunakan untuk mengetahui posisi tingkat pertumbuhan pasar pada Sekolah Tinggi berdasarkan market share. Matriks BCG dapat ditentukan oleh dua faktor yaitu: market growth rate, yang ditunjukkan pada sumbu vertical; relative market share, yang ditunjukkan pada sumbu horizontal.

Analisis tingkat market growth rate pada Sekolah Tinggi, dalam hal ini diukur dari jumlah penerimaan mahasiswa baru dalam dua tahun terakhir, yaitu tahun 2008 dibanding 2009.

Tabel 2 Jumlah Penerimaan Mahasiswa Baru

\begin{tabular}{lllrrrr}
\hline \multirow{2}{*}{ Perguruan Tinggi } & \multicolumn{7}{c}{ Mahasiswa Baru } \\
\cline { 2 - 7 } & $\mathbf{2 0 0 7}$ & $\mathbf{2 0 0 8}$ & $\mathbf{\%}$ Naik & $\mathbf{2 0 0 8}$ & $\mathbf{2 0 0 9}$ & \% Naik \\
\hline Universitas & 75.801 & 80.539 & 6,25 & 80.539 & 86.253 & 7,09 \\
\hline Sekolah Tinggi & 32.922 & 32.298 & $-1,89$ & 32.298 & 25.838 & $-20,00$ \\
\hline Akademi & 21.690 & 21.356 & 1,54 & 21.356 & 14.168 & $-33,66$ \\
\hline Institut & 13.271 & 6.835 & $-48,49$ & 6.835 & 6.084 & $-10,98$ \\
\hline
\end{tabular}

Sumber: Kopertis Wilayah III - DKI Jakarta (2012)

Tingkat market growth rate berdasarkan tabel di atas untuk Sekolah Tinggi adalah sebagai berikut.

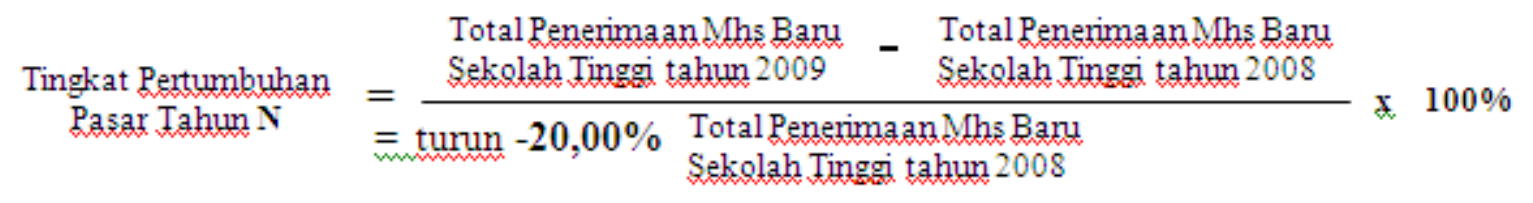

Berdasarkan perhitungan dengan menggunakan matriks BCG tersebut, maka dapat diketahui tingkat pertumbuhan pasar pada Sekolah Tinggi turun sebesar -20,00\% yang berarti bahwa memiliki pertumbuhan pasar yang sangat tidak baik. 
Analisis pangsa pasar Sekolah Tinggi dibandingkan Universitas, dalam perhitungan pangsa pasar relatif (relative marker share) sekolah tinggi terhadap universitas, digunakan total penerimaan mahasiswa tahun ajaran 2008 dan 2009.

$$
\begin{aligned}
& \text { Total Penerima an Mhs Baru } \\
& \underset{\text { Pangsa. Pasar }}{\text { Relatif thn 2008 }}=\frac{\text { Sekolah Tinggi tahun 2008 }}{\begin{array}{l}
\text { Total Penerimaan.Mhs Baru } \\
\text { Universitas tahun 2008 }
\end{array}}=\frac{32.298}{80.539}=0.40<1 \\
& \text { Total Penerimaan Mhs Baru } \\
& \underset{\text { Relatif thn 2009 }}{\text { Pangsa. Par }}=\frac{\text { Sekolah Tingg tahun 2009 }}{\text { Total PenerimaanMhs Baru }}=\frac{25.838}{86.253}=0.29<1 \\
& \text { Universitas tahun } 2009
\end{aligned}
$$

Berdasarkan perhitungan di atas dapat diketahui Sekolah Tinggi memiliki pangsa pasar relatif lebih rendah dibandingkan Universitas karena nilai pangsa pasarnya kurang dari 1, sedangkan pangsa pasar Sekolah Tinggi mengalami kemunduran sebesar 0,11.

Analisis pangsa pasar Sekolah Tinggi dibandingkan Akademi adalah sebagai berikut.

$$
\begin{aligned}
& \text { Total Penerimaan. Mhs Baru } \\
& \underset{\text { Relatif . Pasar } 2008}{\text { Rangsa }}=\frac{\text { Sekolah Tinggi tahun 2008 }}{\begin{array}{l}
\text { Total Penerima anMhs Baru } \\
\text { Alademi tahun 2008 }
\end{array}}=\frac{32.298}{21.356}=1,51>1 \\
& \text { Total Penerimaan. Mhs Baru } \\
& \underset{\text { Relatif thn 2009 }}{\text { Pangsa Pasar }}=\frac{\text { Sekolah Tinggi tahun 2009 }}{\text { Total Penerimaan.Mhs Baru }}=\frac{25.838}{14.168}=1,83>1 \\
& \text { Ak a demi tahun } 2009
\end{aligned}
$$

Berdasarkan perhitungan tersebut diketahui sekolah tinggi memiliki pangsa pasar relatif lebih tinggi dibandingkan Akademi karena nilai pangsa pasarnya lebih dari 1.

Analisis pangsa pasar Sekolah Tinggi dibandingkan Institut adalah sebagai berikut.

$$
\begin{aligned}
& \text { Total Penerimaan. Mhs Bary }
\end{aligned}
$$

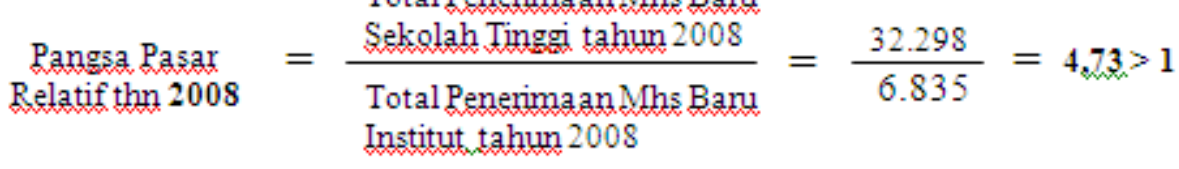

$$
\begin{aligned}
& \text { Total Penerima an Mhs Baru } \\
& \underset{\text { Relatif thn 2009 }}{\text { Pangsa. Pasar }}=\frac{\text { Sekolah Tinggi tahun 2009 }}{\text { Total PenerimaanMhs Baru }}=\frac{25.838}{6.084}=4,25>1 \\
& \text { Institut tahun } 2009
\end{aligned}
$$

Berdasarkan perhitungan tersebut diketahui sekolah tinggi memiliki pangsa pasar relatif lebih tinggi dibandingkan Institut karena nilai pangsa pasarnya lebih dari 1.

Rata-rata Pangsa pasar relatif Sekolah tinggi untuk tahun 2008 adalah $(0,40+1,51+4,73) / 3=$ 2.21. Sedangkan rata-rata Pangsa pasar relatif Sekolah tinggi untuk tahun 2009 adalah $(0,29+1,83+4,25) / 3=2.12$. 


\section{Analisis Posisi Matriks BCG pada Sekolah Tinggi}

Tingkat pertumbuhan pasar pada umumnya dibedakan berdasarkan klasifikasi tinggi dan rendah, sedangkan posisi relative competitor dibedakan berdasarkan market share antara 1,5x dan 4,0x sehingga tergolong tinggi (high) disebut pemimpin (leader). Berdasarkan dari perhitungan tingkat pertumbuhan pasar pada STMIK Widuri, maka diperoleh hasil sebesar -20\%. Ini berarti bahwa tingkat pertumbuhan pasar relative rendah.

Dari perhitungan pangsa pasar relatif pada tahun 2008 didapat hasil sebesar 2,21x dan pada tahun 2009 didapat hasil sebesar 2,12x dan berdasarkan dari kedua hasil tersebut, maka dapat digambarkan bahwa posisi STMIK Widuri pada matriks BCG dapat dilihat pada gambar berikut.

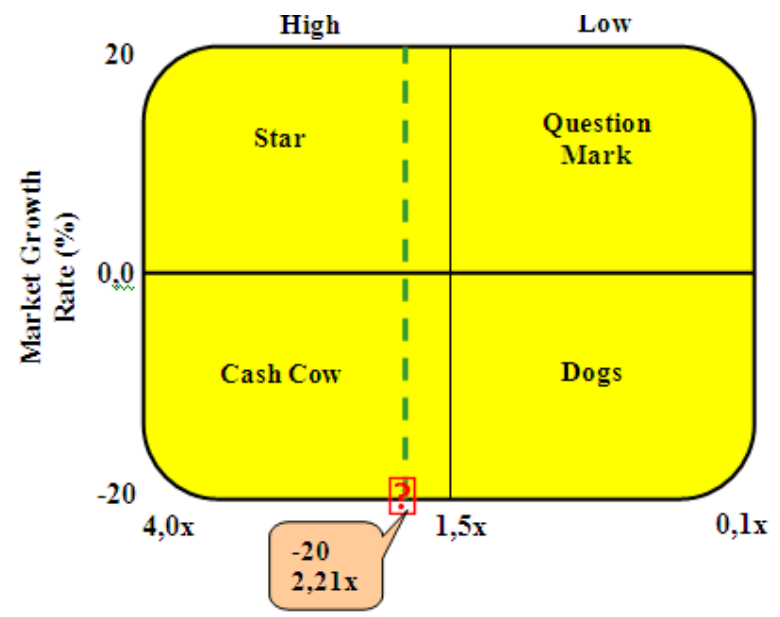

Gambar 2 Matriks BCG Posisi Sekolah Tinggi 2008

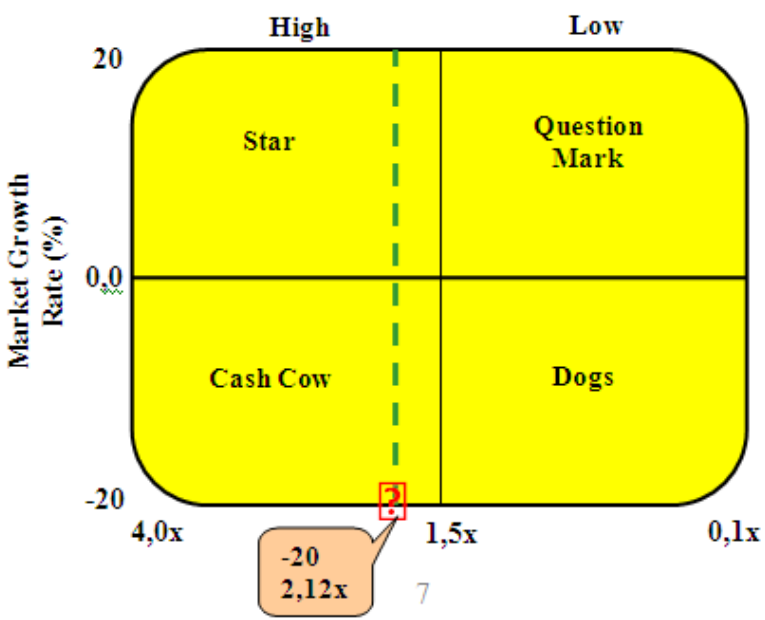

Gambar 3 Matriks BCG Posisi Sekolah Tinggi 2009

Berdasarkan pada kedua gambar matriks BCG posisi dari Sekolah Tinggi pada 2008 dan 2009 berada pada posisi Cash Cow (sapi perah) yang menunjukkan bahwa posisi Sekolah Tinggi memiliki pangsa pasar relatif tinggi bersaing, tetapi bersaing dalam industri yang pertumbuhannya lambat. Disebut Sapi perah karena Sekolah Tinggi menghasilkan kas lebih dari yang dibutuhkan, mereka sering kali diperah. Banyak sapi perah saat ini adalah bintang masa lalu. Kuadran sapi perah, dalam hal ini, Sekolah Tinggi harus dikelola untuk mempertahankan posisi kuatnya selama mungkin. 
Pada posisi ini maka strategi pengembangan produk atau diversifikasi konsentris dapat menjadi strategi yang menarik untuk Sekolah Tinggi yang kuat. Akan tetapi, ketika divisi sapi perah menjadi lemah, retrenchment atau diverstasi lebih sesuai untuk diterapkan.

\section{SIMPULAN}

Sesuai hasil perhitungan Matriks BCG, maka Sekolah Tinggi berada di kuadran III (Cash Cow) karena memiliki posisi pangsa pasar relatif yang rendah. Akan tetapi, mereka bersaing dalam industri yang bertumbuh pesat. Pada saat perusahaan mendapatkan penilaian Cash Cow, ini berarti bahwa dapat tidaknya perusahaan melanjutkan bisnis yang sedang dijalankan sangat bergantung misalnya pada kondisi keuangan yang ada. Hal tersebut dikarenakan bahwa perusahaan memerlukan tambahan dana untuk meningkatkan pangsa pasar disaat pertumbuhan pasar dari bisnis yang dijalankannya tinggi.

Pada posisi Cash Cow, Sekolah Tinggi dapat memilih untuk melakukan strategi melalui promosi di antaranya: melalui website di tiap-tiap sekolah tinggi dengan memberikan informasi yang selengkap dan semenarik mungkin; kerjasama dengan alumni tiap sekolah tinggi; pembuatan brosur; papan reklame di tempat-tempat yang strategis dan mudah dilihat; mengikuti pameran pendidikan baik yang diadakan instansi negeri maupun swasta; potongan pembayaran uang kuliah; kerjasama dengan Sekolah Menengah Umum dan sederajat; dan meningkatkan brand image sekolah tinggi terhadap perguruan tinggi lainnya.

Dari penjelasan tersebut diharapkan dengan melakukan kegiatan promosi jumlah penerimaan mahasiswa baru akan meningkat, dan juga pada akhirnya posisi perusahaan dapat bergeser ke posisi kuadran Star.

\section{DAFTAR PUSTAKA}

Barnett, R. A. (1990). The Idea Of Higher Education. London: Open University Press.

Barnett, R.A. (1994). The Limits of Competence: Knowledge, Higher Education and Society. London: Open University Press.

Bettis, R. A. \& Hall, W. K. (1981). Strategic Portfolio Management in the Multibusiness Firm. California Management Review, 24(1): 23-38.

David, F. R. (2006). Manajemen Strategis, Konsep. Edisi 10 (terjemahan). Buku 1. Jakarta: Salemba Empat.

Direktori Perguruan Tinggi Swasta Kopertis Wilayah III - Jakarta tahun 2008, Departemen Pendidikan Nasional.

Hambrick, D. C., MacMillan, I. C., and Day, D. L. (1982). Strategic Attributes and Performance in the BCG Matrix--A PIMS-Based Analysis of Industrial Product Businesses. Academy of Management Journal. Vol 25, no. 3, 510531. 
Hitt, M.A., Ireland, R. D., \& Hoskisson,R.E. (2001). Strategic management:competitiveness and globalization. $4^{\text {th }}$ ed. Cincinnati, Ohio: South-Western College Publishing/Thomson Learning. http://faculty.unlv.edu/phelan/Research/BCG.pdf - BPSPAP12482 (diakses 11 Januari 2013).

Human, G., and Naudé, P. (2009). Exploring The Relationship between Network Competence, Network Capability and Firm Performance: A Resource-Based Perspective in an Emerging Economy. Journal Management Dynamics. Vol. 18, No. 1, 2009.

Ishikawa, I. (2008). The Source of Competitive Advantage and Entrepreneurial Judgment in the Resource-based View: Insights from the Austrian School Perspective, Journal of Strategic Management Education 4: 91-116. Senate Hall Academic Publishing.

Ivy, J. (2001). Higher Education Institution: a Correspondence Analysis approach. The International Journal of Educational Management, 15(6/7).

Kementerian Pendidikan Nasional, (2010), Direktori Perguruan Tinggi Swasta, Kopertis Wilayah III, Jakarta, Kopertis Wilayah III, Jakarta.

Klein, A. (2011). Corporate Culture: Its Value as a Resource for Competitive Advantage. Journal of Business Strategy, Vol. 32, No. 2, pp. 21-28. ISSN 0275-6668.

Lakitan, B. (2012). Riset untuk peningkatan daya saing Perguruan Tinggi. Rakornas Penelitian dan Pengabdian Kepada Masyarakat, Kementrian Pendidikan dan Kebudayaan, Yogyakarta, 20 Januari 2012.

Nizam. (2012). Pengembangan pendidikan tinggi, untuk kemandirian dan daya saing bangsa , Sekretaris Dewan Pendidikan Tinggi, Rakornas, Kemendikbud, Yogyakarta.

O’Cass, A., Voola, R. (2011). Explications of Political Market Orientation and Political Brand Orientation Using the Resource-based View of the Political Party. Journal of Marketing Management. Vol. 27, Nos. 5-6, May, pp. 627-745. pada CV. Turangga Mas Motor. Jakarta: Skripsi, Universitas Guna Darma.

Peteraf, M. A. (1993). The Cornerstones of Competitive Advantage: a Resource-based view. Strategic Management Journal. Vol. 14, No. 3, pp. 179-191.

Porter, M. E. (1985). Competitive Advantage: Creating and sustaining, superior performance, e-book, the free press.

Rangkuti, F. (2006). Analisis SWOT Teknik Membedah Kasus Bisnis. Jakarta: Gramedia Pustaka Utama.

Sekaran, U., and Bougie, R. (2009). Research Methods for Business, A Skill Building Approach. Fifth edition. United Kingdom: John Wiley \& Sons.

The BCG Matrix revisited: A computational approach

Tilaar, H., A. R. (2008). Agenda Pendidikan Nasioanl dalam Perspektif Abad 21. Yogyakarta: Terra, Indonesia.

Widyatmini dan Fajar, M. F. (2008). Analisis Matriks BCG pada Strategi Pemasaran Produk 